Check for updates

Cite this: Mater. Chem. Front., 2019, 3, 955

DOI: $10.1039 / \mathrm{c} 9 q m 90019 e$

rsc.li/frontiers-materials

\section{Correction: Highly-efficient semi-transparent organic solar cells utilising non-fullerene acceptors with optimised multilayer $\mathrm{MoO}_{3} / \mathrm{Ag} / \mathrm{MoO}_{3}$ electrodes}

\author{
Guangjun Sun, ${ }^{a}$ Munazza Shahid, ${ }^{a}$ Zhuping Fei, ${ }^{\mathrm{b}}$ Shenda $\mathrm{Xu},{ }^{\mathrm{c}}$ Flurin D. Eisner, ${ }^{\mathrm{d}}$ \\ Thomas D. Anthopoulos, ${ }^{e}$ Martyn A. McLachlan ${ }^{b}$ and Martin Heeney*a
}

Correction for 'Highly-efficient semi-transparent organic solar cells utilising non-fullerene acceptors with optimised multilayer $\mathrm{MoO}_{3} / \mathrm{Ag} / \mathrm{MoO}_{3}$ electrodes' by Guangjun Sun et al., Mater. Chem. Front., $2019,3,450-455$

The authors regret that the name of Thomas D. Anthopoulos was not spelled correctly in the original manuscript. The corrected name is shown in the author listing above.

The Royal Society of Chemistry apologises for these errors and any consequent inconvenience to authors and readers.

\footnotetext{
${ }^{a}$ Department of Chemistry and Centre for Plastic Electronics, Imperial College London, SW7 2AZ, UK. E-mail: m.heeney@imperial.ac.uk

${ }^{b}$ Institute of Molecular Plus, Tianjin Key Laboratory of Molecular Optoelectronic Science, Tianjin University, Tianjin, 300072, P. R. China

${ }^{c}$ Department of Materials and Centre for Plastic Electronics, Imperial College London, London SW7 2AZ, UK

${ }^{d}$ Department of Physics and Centre for Plastic Electronics, Imperial College London, London SW7 2AZ, UK

${ }^{e}$ Division of Physical Sciences and Engineering, King Abdullah University of Science and Technology, Saudi Arabia
} 